\title{
STEM-Discovery - An Integrated Approach to DESIGN
}

Dr. Heath Tims, Louisiana Tech University

Dr. Kelly B. Crittenden, Louisiana Tech University

Dr Kelly Crittenden is a member of Louisiana Tech University's Integrated STEM Education Center (ISERC), and the Harrelson Family Professor of engineering. He earned his PhD and BS in BioMedical Engineering in 2001, and 1996 respectively. Dr Crittenden's interests lie in K-12 outreach, developing project-driven curricula, and product design. 


\title{
STEM-Discovery - An Integrated Approach to DESIGN
}

\begin{abstract}
Faculty members from the College of Engineering and Science teamed up with the College of Business and the College of Liberal Arts to develop an engaging experience aimed at high school students and teachers. By including and focusing on teachers, the program will ultimately have broader impact on much greater number of students for years to come. Prior to the camp, teachers are led through Professional Development activities that model the camp experience. This allows for teachers to provide a deeper context for the students that attend.

During the summer of 2015 the camp was piloted at Louisiana Tech University with 12 teachers and 34 students. The STEM-Discovery camp was a natural expansion of the TechSTEP and Cyber Discovery program developed by Louisiana Tech University. The camp consists of discussion sessions, hands on labs, programming exercises, team-building experiences, communication skills, and fundamental STEM topics in order to show a broad perspective of design.
\end{abstract}

Teams of teachers and students are motivated to understand fundamental STEM topics within the context of interesting design challenges. Additionally, teams are exposed to key enabling technologies of engineering design software and modern prototyping equipment and tools. This builds a spirit of teamwork while enhancing both oral and written communication skills.

In order to design content that provided these educational objectives, the Project Execution Team, along with the content experts in each of the three primary threads followed the DESIGN model, proposed in this project. DESIGN can be demonstrated as: Describing, Exploring, Selecting, Implementing, Gaging, and repeating $\mathrm{N}$ number of times.

\section{Introduction}

Numerous publications have expressed concern regarding preparedness of our students to pursue engineering and science degrees (for example, Rising Above the Gathering Storm ${ }^{1}$, The Engineer of $2020^{2}$, and Educating the Engineer of $2020^{3}$ ). Clearly, there is a well-defined need for increased enrollment in and graduation from university science, technology, engineering, and mathematics programs. Moreover, there is a critical need for partnerships between universities and K12 schools to

"Science and mathematics education has truly reached a critical juncture. It is imperative that we find creative ways to improve the delivery of the fundamental math and science our children need in order to be competitive in the emerging global environment." - Wayne Williams Superintendent, WPSB increase the mathematics and science abilities of high school graduates - preparing them for any career path, particularly in STEM disciplines.

Designing and implementing project-driven courses in STEM fundamentals is the hallmark of the Integrated STEM Education Research Center (ISERC) at Louisiana Tech University. ISERC has an established record of engaging high schools with exciting STEM curricula. The curricula 
developed includes weekend workshops focusing on engineering and science fundamentals, summer camps for both students and faculty interested in cyber sciences, and a robotics-centered high school physics curriculum. In all cases, relationships are built with teachers through professional development. These established relationships with teachers in the region, which include buy-in from principals and superintendents, provide a foundation for STEM-Discovery. The TechSTEP ${ }^{4}$ and Cyber Discovery ${ }^{5}$ programs use professional development of high school teachers in science and mathematics as a means to develop lasting relationships between university faculty and teachers in the surrounding region. Since the beginning of these projects, a $33 \%$ increase in the number of students enrolling in STEM degrees at Louisiana Tech University from high schools which participate has been seen ${ }^{6}$.

Since STEM issues cut across all aspects of our lives, our educational efforts have taken a holistic view in integrating science, mathematics, and engineering with business, humanities and liberal arts, including political science, history, ethics, social sciences, and psychology. From professional development of high school teachers to research and development, we have fostered a truly collaborative environment that is providing an avenue for the recruitment of students into STEM-related fields of study. STEM-Discovery focuses on research in STEM learning as well as developing and fostering competitive, knowledgeable, and ethnically diverse talent pools.

\section{Project Description}

This STEM-Discovery design camp and competition focuses on both teachers and students. The weeklong camp serves as a testbed for developing sustainable modules that use virtual learning environments as a delivery mechanism for engaging a broader audience of students. By involving and focusing on teachers, instead of just students, the program ultimately has a broader impact on much greater number of students for years to come. Research, such as the "STEM Perception: Student \& Parent Study" shows that high school is still the primary time that STEM students decided to study STEM. The target audience in this initiative is students in their junior and senior year of high school. This is a critical time in a student's decision as to where to attend and what to study. Many other successful programs focus on younger students to intervene in critical decision making times.

For this project we paired schools that have been a part of ongoing K-12 outreach programs with additional schools that have a larger percentage of underrepresented groups in their general population. In the initial pilot, participating High Schools sent two teachers and six students to the STEM-Discovery camp. Teachers were urged to select student teams that balance academic disciplines with roughly half having interests in science/math and the other half in other fields.

Teacher workshops were used to guide teachers through the engineering design process, as well as the content that would be covered in the weeklong camp that they would attend with their students. These workshops provide critical feedback from teachers on the student design competition that we held at the camp. The teachers then guide their students with the help of university faculty at the STEM-Discovery camp, that was held during the summer. The culminating event for the weeklong camp was a design competition held at Louisiana Tech University. 
Through STEM-Discovery, the integration of topics across the disciplines is achieved by carefully selecting the right content, assignments, and projects to coincide with the STEM content being discussed. This STEM camp appeals to many of the students that are underrepresented in traditional STEM disciplines as well. By allowing students to see and experience the who, what, when, and why of their designs, they gain a greater understanding of the societal impact of design and the STEM disciplines.

The professional development workshops and the camp consisted of two main threads: engineering and business. The engineering thread included how design is accomplished, the fundamentals involved in design, as well as the tools needed for prototyping designs. The business thread included marketing as well as the financial aspects of design. In addition to these two main threads, the need for the aesthetic appeal of products and the communication of the technical aspects of design were included. Additionally, communication related to all aspects of design helps to showcase connections between engineering and business. Key threads of the curriculum are inter-woven to show the connectivity between engineering, design, business, and communication. The threads consisted of using real-world design challenges for each day of the camp to motivate the fundamental STEM topics. Additionally, students and teachers were exposed to enabling technologies and software, as well as prototyping equipment such as vinyl cutting, $3 \mathrm{~d}$ printing, laser scanning, vacuum forming, and vector graphics.

\section{Phases of U-Discovery Model: Initiate, Broaden and Deepen Understanding}

Three separate TechSTEP projects have been implemented successfully over the past 10 years, and STEM-Discovery draws heavily from this experience. In the TechSTEP program, these projects are used as recruiting programs for high school students and as professional development for high school teachers. As a professional development technique, the primary goal is to engage the teachers in the content by working together to motivate their students to consider the relevance of and connections between the high school science and mathematics courses they are studying. By working in collaborative teams, the teachers gain increased understanding of these same connections and are better prepared to answer the "Why do I need to know ? ? " questions from high school students. The TechSTEP programs have employed our u-Discovery ${ }^{4}$ model as the backbone of their structure.

The first phase of the u-Discovery model is to Initiate Understanding. In this phase, learners are taken on a guided tour of a system; typically this means constructing a real-world analog from detailed plans and simple materials. It is important that a system is chosen where multiple connections can be explored. For students and teachers in the Initiate Understanding phase, the fundamentals of the project are demonstrated and a foundation is established for future phases.

In the Broaden Understanding phase of the u-Discovery model, learners are taken through an engineering design process in the context of a challenge related to the system they constructed in the Initiate Understanding phase. Having worked through a detailed construction and analysis process for a system, the learners are now in a position to consider how to design a similar system for a different purpose. For example, in the $R C$ Car project, teachers and students are given an engineering design challenge requiring them to design a remote controlled vehicle that will be able to navigate a course. The challenge is that there are multiple design objectives as the 
vehicle will be used in two competitions, a race and a load carrying competition. These multiple objectives require that participants be led through an analysis of the relationship between motor RPM and car speed depending on how they power their wheels. Teachers gain a better understanding of how all the academic disciplines integrate into real problems; their students are able to appreciate the value of multiple subject areas and the relevance of mathematics and science in the solution process of real problems.

The final, Deepen Understanding, phase of the u-Discovery model is accomplished by students being a part of a deeper experience that takes the form of a real challenge that is fundamentally tied to the previous phases. Requiring student teams to synthesize what they've learned in the Initiate and Broaden phases, the high school students inevitably succeed in going deeper, but in a more direct task-specific setting. Guided by their college-student mentors and high school teachers, these student teams develop intriguing systems to address the challenges presented to them. Specifically, for the RC Car project, student teams cut their vehicle chassis using modern prototyping equipment, build parts for their chassis using a rapid prototyping machine, and even construct the vehicle body. Their overall vehicle designs must incorporate the elements from previous phases, in particular, the motor and microcontroller.

\section{DESIG $^{\mathbf{N}}$}

Specific educational objectives are accomplished through the STEM-Discovery Design Camp and Competitions, as well as the Professional Development workshops. Specific educational objectives for the design competitions are given below:

- To complete projects that motivate the understanding of fundamental STEM topics within the context of interesting real-world design challenges.

- To expose students to the key enabling technologies of engineering design software (solid modeling, Illustrator, SketchUp).

- To train students in using modern prototyping equipment (low cost $3 \mathrm{~d}$ printing, vinyl cutting, vacuum forming) and tools.

- To require that students work in teams, give presentations, and write reports, thus developing both their oral and written communication skills.

In order to design content that provided these educational objectives, the Project Execution Team, along with the content experts in each of the three primary threads met multiple times to provide an initial layout of the project content. The team followed the DESIGN ${ }^{\mathrm{N}}$ odel, proposed by one of the Project Execution Team members. This is a model that builds upon previous successful projects, but is a new iteration that was piloted for STEM-Discovery. DESIG ${ }^{\mathrm{N}}$ can be demonstrated as: Describing, Exploring, Selecting, Implementing, Gaging, and N which represents numerous times repeating some or all of the previous steps in the process. Describing the problem and solution includes making a formal problem statement and a set of design specifications. Exploring looks at brainstorming potential solution, which can include existing solutions. Selecting a solution requires the use of a quantitative way of decision making, such as the Pugh method or a decision matrix. Implementing the selected solution requires the designing and building of a prototype. Gaging tests the prototype against the stated design specifications. With all designs it is important to remember that it is an iterative process, ${ }^{\mathrm{N}}$, that can require repeating a stage $\mathrm{N}$ number of times, and in some cases requires starting back at the Describing stage. 
As part of the design camp, students are presented with multiple design challenges. All of the challenges for the camp build to a culminating final event that allows teacher and student teams the opportunity to showcase and communicate what they have done. Each session is integrated with all of the core content threads, and builds upon skills that the teams are learning throughout the week.

The initial challenge presented to students is the "Apollo 13 Challenge". Apollo 13 is the NASA mission in which the astronauts on Apollo 13 had to quickly improvise an air scrubber from the parts they had on hand in order to have breathable air. In a similar vein, this challenge requires student teams to use a box of seemingly random supplies to assemble a vehicle that can traverse a room. Students are initially given the challenge with minimal instructions,

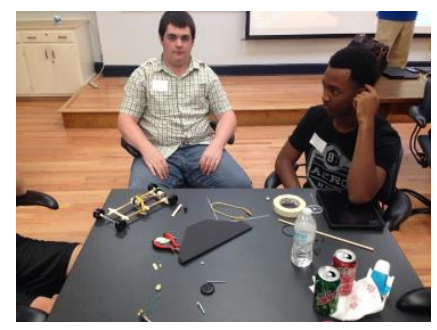
and following the Demonstration of the vehicle challenge; a discussion is held to stress the importance of team communication and organization. The concepts of Describing the problem by understanding the task requirements and looking over the parts available, while Exploring and brainstorming the possible solutions as a team will lead to Selecting an appropriate subset of parts that can be used for Implementing. This activity is used as a low-barrier kickstart to the STEM-Discovery experience.

Teams are led through improvisation and team building exercises by their teachers. Teams are paired based on the mentor and peer school pairing. Teachers use methods and approaches that they were taught as part of the Professional Development workshops to lead their student teams. Following the team building exercises, each team is given a box of parts that will be used to build the chassis of their STEM-Discovery remote controlled vehicle. This approach is used to

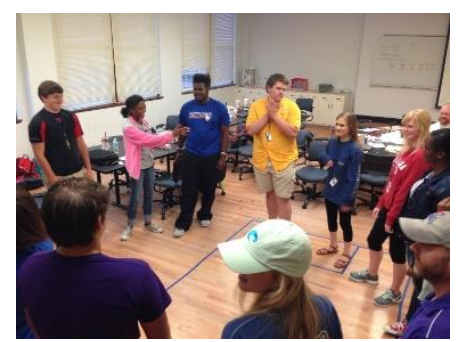
demonstrate a progression of the Apollo 13 challenge and allows for teams to use new communication approaches learned within their teams. Additionally, at the midpoint of the camp, teams are lead through additional team building activities. This allows for teams to use experiences from the first part of the camp to serve as tangible examples of the need for teamwork, and also provides additional training that can be used for the remainder of the camp.

The robotics/engineering portion of the camp presents material on how to configure and program the BASIC Stamp microcontroller used to control the STEM-Discovery vehicles that the students are designing. Designing a remote control car allows for the fundamental concepts that are needed for programming to be taught within a context of a real-world problem. The BASIC Stamp and Board of Education ${ }^{8}$ platform utilized provide the enabling technology for controlling the

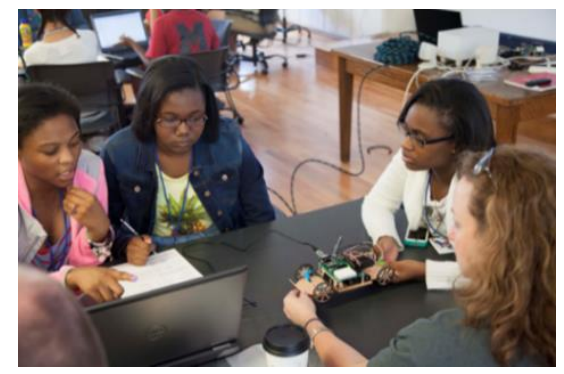
vehicle. Students use multimeters to measure voltage and current in simple circuits which each student constructs on the breadboard of their own vehicle. These circuits allow for measurement of fundamental concepts of voltage, current, and power. Students additionally write BASIC 
computer programs causing LEDs to blink with specified timings to showcase concepts of problem solving and logic.

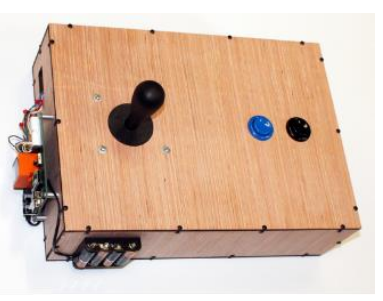

Students extend their skills by building a remote that incorporates a low cost wireless module. This remote is used as an enabling technology to wirelessly control the vehicle and a crane that the students fabricate. The teams use modern prototyping equipment to make all of the parts that are used during the camp. Additionally, students are tasked with the aesthetic design of their car. Students are led through content sessions on the value of design, sketch modeling, branding and visualization, graphics, and rendering aesthetics.

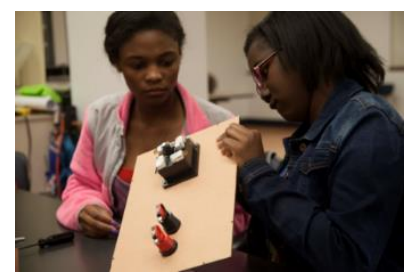

In addition to content sessions that showcase design fundamentals, students are exposed to modern prototyping equipment. Demonstrations of modern prototyping tools allow students to create tangible products needed to tackle the real-world problem they are trying to solve. Students are not only exposed to this equipment, but are also able to work with the tools and equipment as a team to develop the graphical appeal that is needed for the business portion of the project. Evening sessions of technology demonstrations (laser cutting, 3d printing, vacuum forming, vinyl cutting) provide students with an opportunity to be creative and experiment with new prototyping tools. As part of

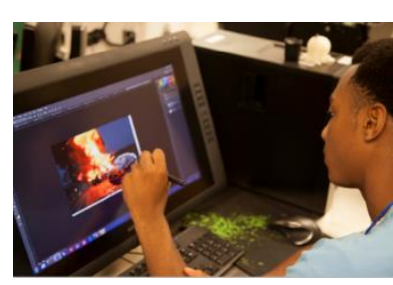
the project, students are tasked with designing their own STEM-Discovery

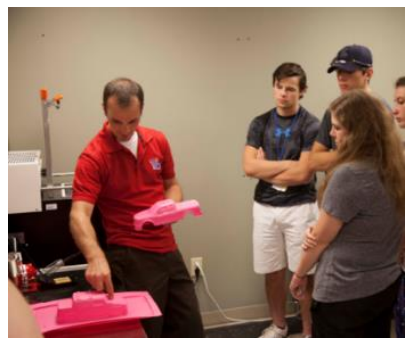
vehicle body. Students use prototyping equipment and hand tools to shape the bodies, which are ultimately vacuum formed. The teams then use skills that were taught in the content sessions to brand and develop a visual identity for their team.

The final content thread that was part of the STEM-Discovery camp is the Business Model Canvas $\left(\mathrm{BMC}^{9}\right)$. The student and teacher teams were additionally tasked with creating a business model for their product. Each team designed a robotic competition that could be held at their school, and they presented a business pitch of how to run this event. The concept was to use the technology and fundamental skills from the STEM-Discovery camp as a testbed for what a competition could look like at their school. Content sessions were held to present the idea of the Business Model Canvas. The BMC is a roadmap that can guide entrepreneurs in the development of a business model for their product or service. Content experts from across the university presented mini-sessions to teach the teams how to develop a marketing plan, how to gather market data, and how to pitch their ideas. The business thread serves as a way to weave the other threads (engineering and design) together. The model presented can be used for a product or a service. For this camp, the teams presented the Business

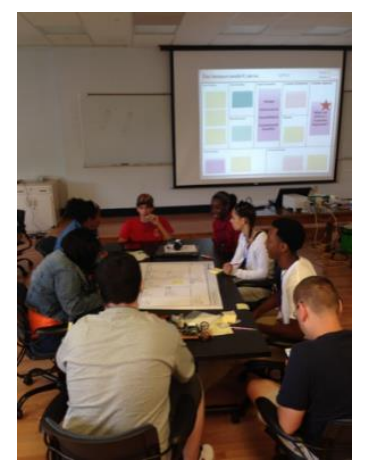
Model Canvas of a non-profit competition that would showcase STEM at their schools. The inclusion of the BMC provides a broader perspective on what a successful design includes. Much of the content in the business thread focuses on written and oral 
communication of ideas. Teams present their ideas throughout the week in many different formats: presentations, posters, and demonstrations.

The entire STEM-Discovery camp is designed to expose students and teacher teams to some of the key enabling technologies, which drive the need for STEM fundamentals. The camp is set up in a competitive environment to promote a spirit of teamwork. An additional key element to the competition is that teams must communicate what they have done.

The DESIG ${ }^{\mathrm{N}}$ model also worked in developing the content for the STEM-Discovery project. Each of the teacher workshops serve as a Gaging element, so that the content is revised for the next teacher and student training. This is the $\mathrm{N}$ repeating component of the $\mathrm{DESIG}^{\mathrm{N}}$ model. The initial content pilot attempted to align the camp days with the individual $\mathrm{DESIG}^{\mathrm{N}}$ components (Describing, Exploring, etc):

\section{Improvisation}

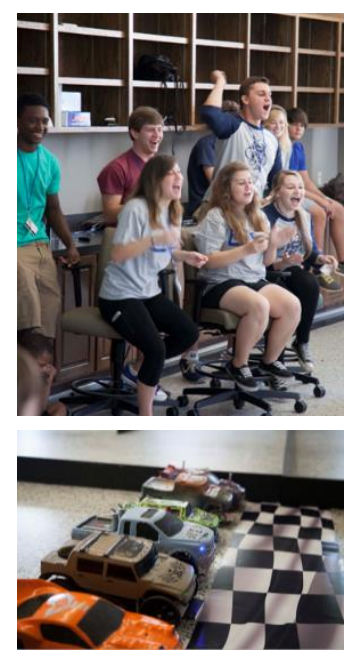

An unexpected outcome of this first STEM-Discovery camp experience is the positive effect on team building that "improv" activities appear to have. (The teacher debrief following the camp, as well as student feedback revealed how well the improv sessions were received.) The project team decided to begin the camp with a social activity. Debriefing sessions from several previous camps have revealed a desire for the participants to have more social activities. One of the newest members of the project team had previous training in improv games and activities, and it was decided to try these same activities with the students and teachers. Improv theatre is built upon the tenet of "Yes, and". When a team member makes an offer, presents an idea, or otherwise provides a new piece of information to the team, the team celebrates and accepts the idea, and builds on it. Through the games that we played, students were encouraged not to preplan their responses, which helped train them to be better listeners. Where we all may have varying degrees of phobia while being looked at while we share our ideas, improv and "Yes, and" build a safe environment of warmth and mutual acceptance that encourage the sharing of new ideas that perhaps seem unjustified at the time.

The larger goal of these exercises was to help students gain awareness of their own self-censoring, or their 'watcher at the gates of the mind'. Students often selfcensor new ideas for fear of how they may be perceived. In the case of the most creative students with interesting ideas, they have learned to withdraw their watcher at the gates and allow the ideas to rush in. The review and inspection of these ideas for merit is deferred. On the other hand, more guarded and perhaps less creative students may experience doubt in the presence of their own novel and interesting ideas. Improv teaches students to support one another by default, and to expect

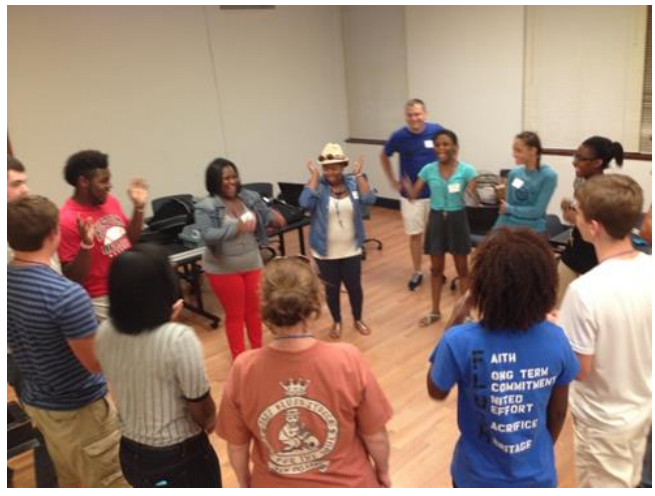
safety and support from one another. 
The experiment in the summer camp proved so successful that an additional improv activity was added to the camp to further help with team dynamics. Additionally, similar activities were added to our college's freshman experience this fall.

\section{Recruiting and Demographics}

As part of the project, two teacher professional development workshops were held in the spring of 2015, as well as the weeklong STEM-Discovery design camp in the summer of 2015. The first teacher Professional Development workshop held in early spring and was attended by 11 teachers representing all 6 schools. The teacher demographics for workshop one are: 7 female teachers, 4 male teachers; 2 African-American/Hispanic/Asian, 9 Caucasian; 8 STEM teachers, 3 business/language arts teachers. Teacher feedback was used following this workshop to further establish the appropriate level of content for the summer design camp.

The second teacher Professional Development workshop was held at the end of the spring and was attended by 12 teachers representing all 6 schools. The teacher demographics for workshop two are: 6 female teachers, 6 male teachers; 2 African-American/Hispanic/Asian, 10 Caucasian; 7 STEM teachers, 5 business/liberal arts teachers. Teacher feedback was also used following this workshop to further refine the summer design camp logistics and content.

The summer Design Camp was held June 15 - June 20, 2015. Teachers were encouraged to bring six students from their school. Demographics were not mandated, but it was suggested that schools find students that were representative of the school demographic. The traditional underrepresented groups vary depending on the demographics of the school. The Design Camp was attended by 12 teachers and 34 students from 6 schools. The teacher demographics for the camp are: 8 female teachers, 4 male teachers; 1 African-American/1 Hispanic, 10 Caucasian; 7 STEM teachers, 5 business/liberal arts teachers. (The difference in the demographics compared to the workshops is a result of teachers that left the participating school and were replaced by an alternate teacher.) The student demographics for the camp are: 14 female students, 20 male students; 13 African-American/Hispanic/Asian, 21 Caucasian. Two students did not arrive with their schools to the camp.

The partner schools: Bossier High School, Benton High School, Parkway High School, Minden High School, Ruston High School, and West Monroe High School were chosen from three regions of north Louisiana. These schools were not only chosen for their geographic recruiting region, but they also match the original proposal demographic pairing of schools in order to further reach under-represented minorities in STEM. Additionally, schools were chosen based on teacher and administrator support for the project.

One key geographic region is the Shreveport/Bossier City area of Louisiana. Bossier High school is an inner-city school that has a 78.8\% minority population. Parkway High School is a school within the city that has a minority population of $28.7 \%$. Benton High School is a more rural suburb with only a $21 \%$ minority population. The other three schools reach across the northern part of the state and are spread across the I-20 corridor. West Monroe is a larger high school in the North-East Louisiana (Monroe/West Monroe) area that only has a minority population of 
$21 \%$, however they have recently built a STEM building at their school to encourage more students to pursue degrees in this area. Minden High School is located in a smaller / more rural town in North Louisiana, and has a minority population of students of 57.4\%. The last school was Ruston High School, which is a school located in the same city as Louisiana Tech University, and has a minority population of $50.6 \%$.

\section{Results and Future Plans}

During and following the weeklong summer camp, the teachers and students were surveyed to provide feedback to the project execution team. Overall, students that participated were very satisfied with the STEM-Discovery camp. Data collected through surveys corroborate their satisfaction. On the Likert scale $1-5$, with 5 being a strongly agree, they rated "I enjoyed camp this week" as the highest. $(\mathrm{M}=4.29, \mathrm{SD}=0.95)$, followed by "I am satisfied with experiences I had this week $(M=4.08, S D=1.02)$. When students were asked about which activities they enjoyed the most, the majority of students $(69 \%)$ reported activities that were STEM components of the camp. Specifically, students enjoyed building (36\%), engineering, graphic design, and programming (14\% each), business and designing (7\% each), and robotics (4\%).

Some evidence indicated students who participated in the STEM-Discovery program already have a strong interest in Science. This is not unexpected given that students who participate are chosen by their teachers, and based on survey data most are already intending to attend postsecondary education. Of student survey participants, $(96 \%)$ reported that they intend to attend college. Of those intending to attend college, (57\%) plan to major in a STEM discipline. Following the camp, students were asked about their academic interests. Student participants reported their degree of interest in Language Arts, Social Studies, Mathematics, and Science on a 6-point Likert scale ( $1=$ Not Interested at All, $6=$ Very Interested $)$. The student participants were most interested in Science $(M=5.43, S D=1.03)$, followed by Mathematics $(M=4.38, S D$ $=1.56)$, Social Studies $(\mathrm{M}=4.09, \mathrm{SD}=1.68)$, and Language Arts $(\mathrm{M}=2.86, \mathrm{~S}=1.42)$.

When trying to look at motivation of students to participate in STEM disciplines, the internal evaluation team developed instrumentation to measure the impact of project activities on student motivation. It is important to remember that the sample size is small, so finding are only preliminary, but the data shows promising results that the STEM-Discovery project may influence changes in intrinsic motivation, grade motivation, and self-efficacy.

When looking at teachers that participated in the STEM-Discovery camp, teachers were satisfied. Data collected through surveys demonstrate their satisfaction. Using a Likert scale, ranging from $1=$ strongly disagree to $5=$ strongly agree, teachers rated a series of statements. They equally rated "I am satisfied with the experiences I had this week" $(\mathrm{M}=4.33, \mathrm{SD}=0.82)$, and "I enjoyed camp this week" $(\mathrm{M}=4.33, \mathrm{SD}=0.52)$. Some of the more important feedback from teachers were the comments. Feedback from the teachers ranged from "Car and design is the best part" to the "Improvisation is great!" to suggestions like "provide earlier feedback from professionals on the business pitch." These comments are critical to the project execution team, and will be used in modifying content for future years.

In future years, the project will expand to additional schools, as compared to the six schools. After piloting the content in the context of a weeklong camp experience, future years will consist 
of teacher Professional Development and Student Discovery weekends will lead selected high school teachers and students through the STEM-Discovery content. Content that was piloted in the camp will serve as the basis for the weekend workshop content. The goal of the teacher workshops and corresponding student Discovery Weekends is that these teachers, with assistance from the university project team, will guide their students through the same content during the academic year. The culminating event for the academic year project will be a design competition.

\section{Acknowledgement and Disclaimer}

Support for this work was partially provided by the National Science Foundation under Award Number IIA-1348314. Any opinions, findings, and conclusions or recommendations expressed in this material are those of the authors and do not necessarily reflect the views of NSF.

\section{Bibliography}

1. National Academy of Engineering. Rising Above the Gathering Storm, The National Academies Press, 2007

2. National Academy of Engineering. The Engineer of 2020: Visions of Engineering in the New Century, The National Academies Press, 2004.

3. National Academy of Engineering. Educating the Engineer of 2020: Adapting Engineering Education to the New Century, The National Academies Press, 2005.

4. Crittenden, K. , A. Boudreaux, J. Nelson, and G. Turner. "TechSTEP: Connecting High School Teachers and Students to Integrated Engineering and Science," Proceedings of the American Society of Engineering Education Meeting, 2008.

5. Tims, H., Turner, G., Deemer, E., Corbett, K. (2012) "Using Cyber Discovery to Assess Change in Student STEM-Related Attitudes," Proceedings of the American Society for Engineering Education, San Antonio, TX (June 12, 2012)

6. Turner, G., Tims, H., Crittenden, K. (2012) "An Index to aid in the development of High School recruitment of future Engineering and Science majors," Proceedings of the American Society for Engineering Education, San Antonio, TX (June 11, 2012)

7. Harris Interactive . STEM Perceptions: Student and Parent Study, 2011.

8. Parallax, Parallax Home Web Site, http://www.parallax.com/, 2016.

9. Osterwalder, A., Pigneur, Y., Smith, A., et al Business Model Generation, Wiley, 2010 